\title{
Phase I/II clinical trial of temsirolimus and lenalidomide in patients with relapsed and refractory lymphomas
}

\author{
Ajay Major, Justin Kline, ${ }^{1}$ Theodore G. Karrison, ${ }^{1}$ Paul A. S. Fishkin, ${ }^{2}$ Amy S. Kimball, ${ }^{3,4}$ Adam M. \\ Petrich, ${ }^{5,6}$ Sreenivasa Nattam, ${ }^{7}$ Krishna Rao, ${ }^{8}$ Bethany G. Sleckman, ${ }^{9}$ Kenneth Cohen, ${ }^{1}$ Koen van \\ Besien, ${ }^{10}$ Aaron P. Rapoport ${ }^{3}$ and Sonali M. Smith ${ }^{1}$
}

${ }^{1}$ University of Chicago, Chicago, IL; ${ }^{2} \mathrm{lllinois}$ Cancer Care, Peoria, IL; ${ }^{3}$ University of Maryland School of Medicine and Marlene and Stewart Greenebaum Comprehensive Cancer Center, Baltimore, MD; ${ }^{4}$ Amgen Inc., Thousand Oaks, CA; ${ }^{5}$ Northwestern University, Chicago, IL; ${ }^{6}$ Daiichi-Sankyo, Basking Ridge, NJ; ${ }^{7}$ Fort Wayne Oncology/Hematology, Fort Wayne, IN; ${ }^{8}$ Southern Illinois University, Springfield, IL; ${ }^{9}$ Mercy Hospital, St. Louis, IL and ${ }^{10}$ Weill Cornell Medicine, New York, NY, USA

\author{
Correspondence: \\ Sonali M. Smith \\ smsmith@medicine.bsd.uchicago.edu \\ Received: $\quad$ April 18, 2021 \\ Accepted: July 22, 2021 \\ Prepublished: July 29, 2021. \\ https://doi.org/10.3324/haematol.2021.278853 \\ @2022 Ferrata Storti Foundation \\ Haematologica material is published under a CC \\ BY-NC license @ @ $\Theta \Theta$
}

\begin{abstract}
The PI3K/Akt/mTOR (PAM) axis is constitutively activated in multiple lymphoma subtypes and is a promising therapeutic target. The mTOR inhibitor temsirolimus (TEM) and the immunomodulatory agent lenalidomide (LEN) have overlapping effects within the PAM axis with synergistic potential. This multicenter phase I/II study evaluated combination therapy with TEM/LEN in patients with relapsed and refractory lymphomas. Primary endpoints of the phase II study were rates of complete (CR) and overall response (ORR). There were 18 patients in the phase I dose-finding study, and TEM 25 mg weekly and LEN 20 mg on day 1 through day 21 every 28 days was established as the recommended phase II dose. An additional 93 patients were enrolled in the phase II component with three cohorts: diffuse large B-cell lymphoma (DLBCL, $n=39$ ), follicular lymphoma ( $F L, n=15)$, and an exploratory cohort of other lymphoma histologies with classical Hodgkin lymphoma ( $\mathrm{CHL}$ ) comprising the majority ( $\mathrm{n}=39$ total, $\mathrm{n}=20 \mathrm{with} \mathrm{cHL}$ ). Patients were heavily pretreated with a median of four (range, 1-14) prior therapies and one-third with relapse following autologous stem cell transplantation (ASCT); patients with $\mathrm{CHL}$ had a median of six prior therapies. The FL cohort was closed prematurely due to slow accrual. ORR were 26\% (13\% CR) and 64\% (18\% CR) for the DLBCL and exploratory cohorts, respectively. ORR for cHL patients in the exploratory cohort, most of whom had relapsed after both brentuximab vedotin and ASCT, was $80 \%$ (35\% CR). Eight $\mathrm{CHL}$ patients (40\%) proceeded to allogeneic transplantation after TEM/LEN therapy. Grade $\geq 3$ hematologic adverse events (AE) were common. Three grade 5 AE occurred. Combination therapy with TEM/LEN was feasible and demonstrated encouraging activity in heavily-pretreated lymphomas, particularly in relapsed/refractory cHL (clinicaltrials gov. Identifier: NCT01076543).
\end{abstract}

\section{Introduction}

Classical Hodgkin lymphoma (cHL) and non-Hodgkin lymphomas (NHL) are typically chemosensitive to early lines of therapy, but relapse is a frequent and often lifethreatening event. Development of novel non-chemotherapy agents for the treatment of lymphoma, including targeted and immunomodulatory agents, presents opportunities for disease control in a more rational approach. The PI3K/Akt/mTOR (PAM) signal transduction pathway is constitutively activated in lymphoma and is a promising therapeutic target that appears to be shared across biologically heterogeneous lymphoma subtypes. ${ }^{1-3}$

Mammalian target of rapamycin (mTOR) is a master regulator of growth and survival in normal and neoplastic cells. ${ }^{3}$ Activation of mTOR is regulated by upstream phosphatidylinositol-3,4,5 kinase (PI3K) and Akt signaling, which pro- motes cell growth, cell survival and proliferation. ${ }^{4}$ Aberrant mTOR activation occurs via several mechanisms in NHL, including PTEN loss in mantle cell lymphoma (MCL), PIK3CA amplification in diffuse large B-cell lymphoma (DLBCL), and PKC $\delta$ or Syk kinase activation in follicular lymphoma (FL). ${ }^{3}$ mTOR activation has also been demonstrated in $\mathrm{cHL}$, likely mediated by mTORC1 and Akt.5,6 mTOR is a particularly attractive therapeutic target given its position as a common downstream regulator for several oncogenic pathways. The first generation mTOR inhibitor temsirolimus (TEM) is currently Food and Drug Administration approved for the treatment of metastatic renal cell carcinoma, and has demonstrated monotherapy activity in several lymphoma subtypes, including MCL, DLBCL, and FL. ${ }^{3,7,8,9}$

In addition to reliance on signal transduction pathways, the tumor microenvironment and immune composition contribute to lymphoma pathogenesis and may augment 
PAM axis deregulation.10,11 Lenalidomide (LEN) is an immune-modulatory agent which enables proteasomal degradation and downregulation of several transcription factors, which then function as oncogenes. ${ }^{12}$ Within the PAM axis, LEN inhibits Akt phosphorylation and VEGF translation. ${ }^{1,13}$ LEN is active in both NHL and $\mathrm{CHL}$, and is frequently tested in combination regimens. ${ }^{14,15}$

Given the promising single-agent activity of both TEM and LEN and the potential for synergistic effects of the two agents on the PAM axis, we conducted a multicenter phase I/II study of combination TEM/LEN therapy in patients with relapsed and refractory lymphomas.

\section{Methods}

This study is an open-label phase I/II multicenter clinical trial of TEM/LEN combination therapy in patients with relapsed and refractory lymphomas. Weekly data and safety monitoring occurred through the University of Chicago Phase II consortium. This clinical trial was registered through the National Cancer Institute as protocol number 8309 (clinicaltrial gov. Identifier: NCT01076543). Study accrual occurred from 2010 to 2015. The protocol was approved by the University of Chicago Medical Center Institutional Review Board (IRB number 09-443-A).

\section{Patient selection and eligibility}

Patients with histologically-confirmed $\mathrm{CHL}$ and $\mathrm{NHL}$ treated with $\geq 1$ prior cytotoxic regimen were eligible. There was no limit to the number of prior therapies allowed, and patients with prior autologous stem cell transplantation (ASCT) were eligible. Chronic lymphocytic leukemia/small lymphocytic lymphoma (CLL/SLL) was excluded due to poor efficacy of single-agent TEM observed previously in this disease. ${ }^{9}$ For the phase II component, patients were grouped into three cohorts: (i) DLBCL; (ii) FL; and (iii) an exploratory cohort of other lymphomas (including cHL, T-cell NHL [T-NHL], marginal zone lymphoma [MZL], lymphoplasmacytic lymphoma [LPL], and MCL). Full inclusion criteria are presented in the Online Supplementary Appendix.

\section{Study design and treatment plan}

For the phase I dose-finding study, TEM was administered intravenously weekly at a dose of $25 \mathrm{mg}$ for all dose levels, and LEN was administered orally on day 1 through day 21 every 28 days at three dose levels: $15 \mathrm{mg}, 20 \mathrm{mg}$, and 25 mg. One cycle was defined as 4 weeks, or 28 days. There was no intrapatient dose escalation. Treatment was administered on an outpatient basis. Patients were treated to intolerance, progression, or discontinuation at physician discretion. Dose-limiting toxicity (DLT) was defined as grade 3 or 4 non-hematologic toxicity, grade 4 thrombo- cytopenia for greater than 7 days (or associated with bleeding or requiring more than 1 platelet transfusion), ANC less than $500 / \mu \mathrm{L}$ for greater than 7 days despite growth factor administration, or any thromboembolic event. DLT was assessed after one cycle of TEM/LEN.

The phase II study accrued patients into the three aforementioned cohorts: DLBCL, FL, and the exploratory cohort of other lymphoma histologies. Patients received therapy for up to 1 year, or until disease progression or development of toxicities requiring treatment cessation. $\mathrm{Pa}-$ tients considered to be at high risk of developing venous thromboembolism received prophylactic aspirin or low molecular weight heparin.

\section{Response and toxicity assessment criteria}

Eligible patients from the DLBCL, FL, and the exploratory cohort were assessed for response to therapy using the 2006 revised response criteria for lymphoma. ${ }^{16}$ Patients with Waldenström macroglobulinemia (WM) were assessed using the consensus recommendations for response. ${ }^{17}$ Response assessments were performed after cycle 2 (week 8), and then every 3 months thereafter. Confirmatory scans were recommended at least 4 weeks following initial documentation of an objective response. Toxicities were graded according to the National Cancer Institute Common Terminology Criteria for Adverse Events, Version 4. Patients were eligible for toxicity reporting if at least one dose of a study drug was administered. Patients were removed from the study if one of the following criteria applied: completion of 52 weeks of therapy, disease progression, unacceptable adverse events, study withdrawal, or eligibility for allogeneic transplantation. Patients who were candidates for allogeneic transplantation after progression on TEM/LEN proceeded directly to transplant without bridging therapy.

\section{Study endpoints and statistical analysis}

The phase I dose-finding study utilized a " $3+3$ " design, and the phase II study accrued patients in a two-stage "minimax" design for each cohort.8 The primary endpoints of the phase II study were rates of complete (CR) and overall response (ORR), and secondary endpoints were duration of response (DOR), progression-free survival (PFS) and overall survival (OS), stratified by histology. PFS was defined as the time from study entry to progression or death from any cause. OS was defined as the time from study entry to death. DOR was defined as the time from the first documented date of response to the date of progression or death, whichever came first. PFS, OS, and DOR were estimated by the Kaplan-Meier method. ${ }^{19}$ Median time to event and associated $90 \%$ confidence intervals were determined using the procedure of Brookmeyer and Crowley. ${ }^{20} \mathrm{~A}$ full description of the null and alternative hypotheses is presented in the Online Supplementary Appendix. 


\section{Results}

\section{Phase I}

Of 18 patients enrolled in the phase I study, 13 were male and five were female, with a median age of 62 years (range, 41-80 years). Of these, 15 patients were evaluable for DLT assessment, with the remaining three patients non-evaluable due to one withdrawing consent before starting treatment, one withdrawing consent after one dose, and one dying of rapid disease progression after one dose. As shown in Table 1, there was one DLT at dose level 1 (grade 4 hypokalemia) and two DLT at dose level 3 (grade 3 diarrhea and grade 3 HSV mucositis). Other grade 3 or 4 adverse events not meeting DLT criteria are as follows, each occurring in one patient: hypokalemia, hypertriglyceridemia, vomiting, urinary tract infection, skin infection, nausea, hypoxia, hyponatremia, diarrhea, and hyperglycemia. Of the 18 patients, there were five with partial responses, three with stable disease, six with progressive disease, and four not adequately assessed. Per protocol, dose level 2 was thus established as the recommended phase II dose: TEM 25 mg weekly and LEN 20 mg on day 1 through day 21 every 28 days. Patients were treated for at least two consecutive 28-day cycles, and patients showing at least stable disease after two cycles were permitted to continue treatment for up to 52 weeks of therapy.

\section{Phase II}

The baseline characteristics for the 93 patients in the phase II study are displayed in Table 2, including 39 patients with DLBCL, 15 patients with FL, and 39 patients in the exploratory cohort. In the DLBCL cohort, six had a prior history of FL and three had a prior history of MZL. In the exploratory cohort, 20 had $\mathrm{CHL}$, nine had T-NHL, five had MCL, four had MZL, and one had WM. Overall, there were 62 males and 31 females, with a median age of 57 years (range, 23-78 years). The cohort was very heavily pre-treated with four (range, 1-14) median prior treatments. A total of 31 patients (33\%) had relapsed following ASCT. In the DLBCL and FL cohorts, all patients had previously received rituximab. In the exploratory cohort, all patients with B-cell NHL had previously received rituximab. For the $20 \mathrm{cHL}$ patients in the exploratory cohort, the median number of prior treatments was six (range, 314), 19 (95\%) had progressed after previous treatment with brentuximab vedotin (BV), and 15 (75\%) had progressed after previous ASCT. The FL cohort was closed prematurely due to slow accrual. The CONSORT diagram for the phase II study is displayed in Online Supplementary Figure S1.

\section{Primary and secondary endpoints}

Primary and secondary endpoints were analyzed for all 93 patients in the phase II study on an intention-to-treat basis. The rates of CR and ORR, and median DOR, PFS, OS, and follow-up for all three cohorts are displayed in Table 3. A waterfall plot of best responses from baseline is displayed in Figure 1. The DLBCL and exploratory cohorts achieved a sufficient number of responses in the first stage to proceed to the second stage of the phase II trial. The FL cohort was terminated due to lack of accrual. A swimmer's plot of treatment duration, best responses, and follow-up for the DLBCL and CHL cohorts is displayed in Figure 2.

In the DLBCL cohort, the ORR was $25.6 \%$ with $12.8 \%$ achieving CR. Twenty-two of the 39 DLBCL patients had germinal center B-cell-like (GCB) DLBCL, and three of those patients responded. Eight of the 39 DLBCL patients had activated $B$-cell-like ( $A B C$ ) DLBCL, and seven of those patients responded. No patients with transformed lymphomas responded to TEM/LEN treatment. The total number of responders, ten of 39 , was not sufficient to reject the null hypothesis of a $30 \%$ response rate. The median DOR of the DLBCL cohort was 13.8 months (90\% confidence interval [Cl]: 4.1-19.0 months). The median DOR was 4.1 months ( $90 \% \mathrm{Cl}: 2.6$ months - not estimable) for GCB versus 13.8 months (90\% Cl: 11.3 months - not estimable) for $A B C$, which was not significant $(P=0.09)$, although this comparison was based on few patients. The median PFS and OS were 7.0 months (90\% Cl: 3.5-8.0 months) and 9.1 months ( $90 \% \mathrm{Cl}$ : 6.0-16.0 months), respectively, as shown in Figure 3. At last follow-up assessment, six patients were alive, 30 had died, and three were

Table 1. Summary of dose levels, number of patients, and dose-limiting toxicities for the phase I study.

\begin{tabular}{|c|c|c|c|c|}
\hline \multirow{2}{*}{ Dose level } & \multicolumn{2}{|c|}{ Dose } & \multirow{2}{*}{ Number of patients } & \multirow{2}{*}{ DLT } \\
\hline & TEM (mg) & LEN (mg) & & \\
\hline-1 & $25 \mathrm{mg}$ & $10 \mathrm{mg}$ & na & na \\
\hline 1 & $25 \mathrm{mg}$ & $15 \mathrm{mg}$ & $\begin{array}{c}8 \\
\text { (2 inevaluable for DLT) }\end{array}$ & grade 4 hypokalemia \\
\hline 2 & $25 \mathrm{mg}$ & $20 \mathrm{mg}$ & $\begin{array}{c}4 \\
\text { (1 inevaluable for DLT) }\end{array}$ & No DLT \\
\hline 3 & $25 \mathrm{mg}$ & $25 \mathrm{mg}$ & 6 & $\begin{array}{c}\text { grade } 3 \text { diarrhea, } \\
\text { grade } 3 \text { HSV mucositis }\end{array}$ \\
\hline
\end{tabular}

DLT: dose-limiting toxicity; TEM: temsirolimus; LEN: lenalidomide; HSV: herpes simplex virus. 
lost to follow-up. Five patients in the DLBCL cohort proceeded to allogeneic transplantation after TEM/LEN therapy, with three reported as alive and two lost to follow-up at last assessment.

The FL cohort $(n=15)$ was slow to accrue and closed pre- maturely, and was therefore not included in the KaplanMeier survival analysis. The ORR was $46.6 \%$ with $33.3 \%$ achieving CR. The median DOR was 26.5 months (90\% Cl:17.6-35.2 months). The median PFS and OS were 27.7 months (90\% Cl: 6.5-35.8 months) and 35.8 months (90\%

Table 2. Baseline patient characteristics for the phase II study.

\begin{tabular}{|c|c|c|c|}
\hline Characteristics & DLBCL & FL & Exploratory cohort \\
\hline $\begin{array}{l}\text { Number of patients } \\
\text { Median age }(y) \\
\text { Age range }(y)\end{array}$ & $\begin{array}{c}39 \\
65 \\
25-78\end{array}$ & $\begin{array}{c}15 \\
61 \\
43-76\end{array}$ & $\begin{array}{c}39 \\
49 \\
23-72\end{array}$ \\
\hline $\begin{array}{l}\text { Sex } \\
\text { Male (\%) } \\
\text { Female }(\%)\end{array}$ & $\begin{array}{l}28(72) \\
11(28)\end{array}$ & $\begin{array}{l}9(60) \\
6(40)\end{array}$ & $\begin{array}{l}25(64) \\
14(36)\end{array}$ \\
\hline $\begin{array}{l}\text { Race } \\
\text { White } \\
\text { Black or African American } \\
\text { Asian } \\
\text { Unknown or declined } \\
\text { American Indian or Alaska Native } \\
\text { More than one race }\end{array}$ & $\begin{array}{c}33 \\
4 \\
1 \\
1 \\
0 \\
0\end{array}$ & $\begin{array}{l}12 \\
2 \\
1 \\
0 \\
0 \\
0\end{array}$ & $\begin{array}{c}29 \\
6 \\
1 \\
1 \\
1 \\
1\end{array}$ \\
\hline $\begin{array}{l}\text { Ethnicity } \\
\text { Hispanic or Latino } \\
\text { Non-hispanic } \\
\text { Unknown or declined }\end{array}$ & $\begin{array}{c}1 \\
37 \\
1\end{array}$ & $\begin{array}{c}1 \\
14 \\
0\end{array}$ & $\begin{array}{c}7 \\
31 \\
1\end{array}$ \\
\hline $\begin{array}{l}\text { Histology } \\
\text { DLBCL } \\
\text { Follicular lymphoma } \\
\text { Hodgkin lymphoma } \\
\text { T-cell lymphoma } \\
\text { Mantle cell lymphoma } \\
\text { Marginal zone lymphoma } \\
\text { Waldenström macroglobulinemia }\end{array}$ & 39 & 15 & $\begin{array}{c}20 \\
9 \\
5 \\
4 \\
1\end{array}$ \\
\hline $\begin{array}{l}\text { Lymphoma characteristics } \\
\text { Germinal center subtype } \\
\text { Non-germinal center subtype } \\
\text { Double hit lymphoma } \\
\text { Double expressor lymphoma } \\
\text { Transformed lymphoma }\end{array}$ & $\begin{array}{c}22 \\
8 \\
3 \\
4 \\
9\end{array}$ & & \\
\hline $\begin{array}{l}\text { Number of prior regimens } \\
1 \\
2 \\
3 \\
4 \\
>4 \\
\text { Median } \\
\text { Range }\end{array}$ & $\begin{array}{c}4 \\
12 \\
5 \\
7 \\
11 \\
3 \\
1-11\end{array}$ & $\begin{array}{c}2 \\
2 \\
4 \\
2 \\
5 \\
3 \\
1-6\end{array}$ & $\begin{array}{c}2 \\
1 \\
9 \\
10 \\
17 \\
4 \\
1-14\end{array}$ \\
\hline $\begin{array}{l}\text { Type of prior therapy } \\
\text { Multiagent chemotherapy (\%) } \\
\text { Radiation (\%) } \\
\text { Rituximab (\%) } \\
\text { Autologous stem cell transplantation (\%) } \\
\text { Brentuximab vedotin (\%) }\end{array}$ & $\begin{array}{c}39(100) \\
9(23) \\
39(100) \\
8(21) \\
0(0)\end{array}$ & $\begin{array}{l}15(100) \\
1(7) \\
15(100) \\
2(13) \\
0(0)\end{array}$ & $\begin{array}{l}39(100) \\
17(44) \\
10(26) \\
21(54) \\
20(51)\end{array}$ \\
\hline
\end{tabular}

FL: follicular lymphoma; DLBCL: diffuse large B-cell lymphoma; y:years. 


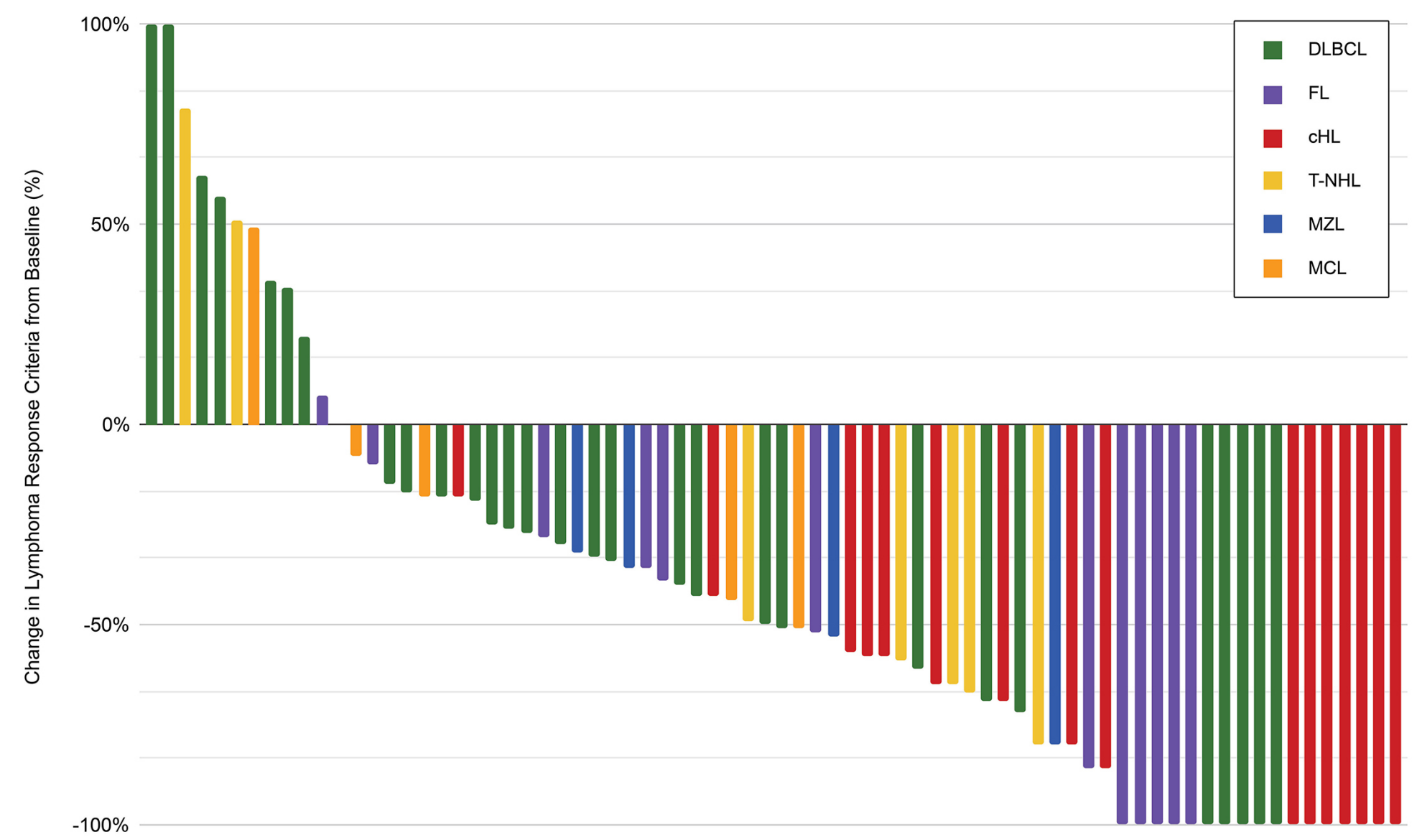

Figure 1. Waterfall plot for best response for evaluable patients in the phase II study by histology ( $n=74)$. Of the 93 patients in the phase II study, 8 patients did not complete 2 cycles of temsirolimus/lenalidomide (TEM/LEN) for pre-specified response assessment, 10 patients did not have reported response data, and 1 patient had Waldenström macroglobulinemia. DLBCL: diffuse large B-cell lymphoma; FL: follicular lymphoma; cHL: classical Hodgkin lymphoma; T-NHL: non-Hodgkin lymphoma; MZL: marginal zone leukemia; MCL: mantle cell lymphoma.

Cl: 18.8 months - not estimable), respectively. At last follow-up assessment, five patients were alive, six had died, and four were lost to follow-up.

When evaluating all patients in the exploratory cohort, the ORR was $64.1 \%$ (CR 17.9\%) and the median DOR was 5.5 months (90\% Cl: 2.6-23.7 months). Among all histologies in this cohort, the total number of responders, 25 of 39, was sufficient to reject the null hypothesis of a $30 \%$ response rate $(P<0.10)$. The median PFS and OS were 7.0 months (90\% Cl: 4.6-9.9 months) and 25.5 months (90\% Cl: 10.8-60.6 months), respectively, as shown in Figure 3. At last follow-up assessment, ten patients were alive, 21 had died, and eight were lost to follow-up.

A substantial portion of patients in the exploratory cohort had $\mathrm{cHL}(\mathrm{n}=20)$. As displayed in Table 3, the ORR for $\mathrm{cHL}$ was $80 \%$ (CR 35\%). The median DOR was 8.1 months $(90 \%$ Cl: 5.1-38.3 months). The median PFS and OS were 9.2 months (90\% Cl: 4.6 - 25.5 months) and 39.6 months (90\% $\mathrm{Cl}: 17.4$ months - not reached), respectively, displayed in Figure 4. Eight $\mathrm{cHL}$ patients (40\%) proceeded to allogeneic transplantation after TEM/LEN therapy. At last follow-up assessment, nine patients were alive, nine had died, and two were lost to follow-up. Notably, six of the eight patients who had received allogeneic transplantation after TEM/LEN were alive at last assessment.

Of the 19 non-cHL patients in the exploratory cohort, nine achieved a PR and none achieved a CR (ORR 47.4\%). Spe- cifically, responses were observed in six of nine patients with T-NHL (67\%) with a median DOR of 2.3 months (90\% $\mathrm{Cl}: 1.8$ months - not reached), in two of four patients with MZL (50\%), in the one patient with WM, and no patients with MCL.

\section{Treatment delivered}

The median number of TEM/LEN cycles delivered was four (range, 1-21). The CONSORT diagram in the Online Supplementary Figure $S 1$ depicts the reasons for treatment discontinuation among all three cohorts. Twelve patients, three in the phase I study and nine in the phase II study, did not complete two cycles of TEM/LEN for the following reasons: adverse effects $(n=6)$, progression of disease $(n=3)$, withdrawal from study $(n=1)$ or death $(n=2)$. Reasons for discontinuing study treatment at any point beyond cycle 2 included toxicity ( $n=21$, see safety and tolerability), progression of disease $(n=36)$, death $(n=3)$, or other $(n=26)$. In this latter category, reasons for the discontinuation of therapy were either to pursue alternative treatment or due to physician or patient decisions. Fifty-one patients required dose reductions, primarily due to hematopoietic toxicities.

\section{Safety and tolerability}

Online Supplementary Table S1 summarizes the AE that occurred in greater than $10 \%$ of patients or that were grade 3 


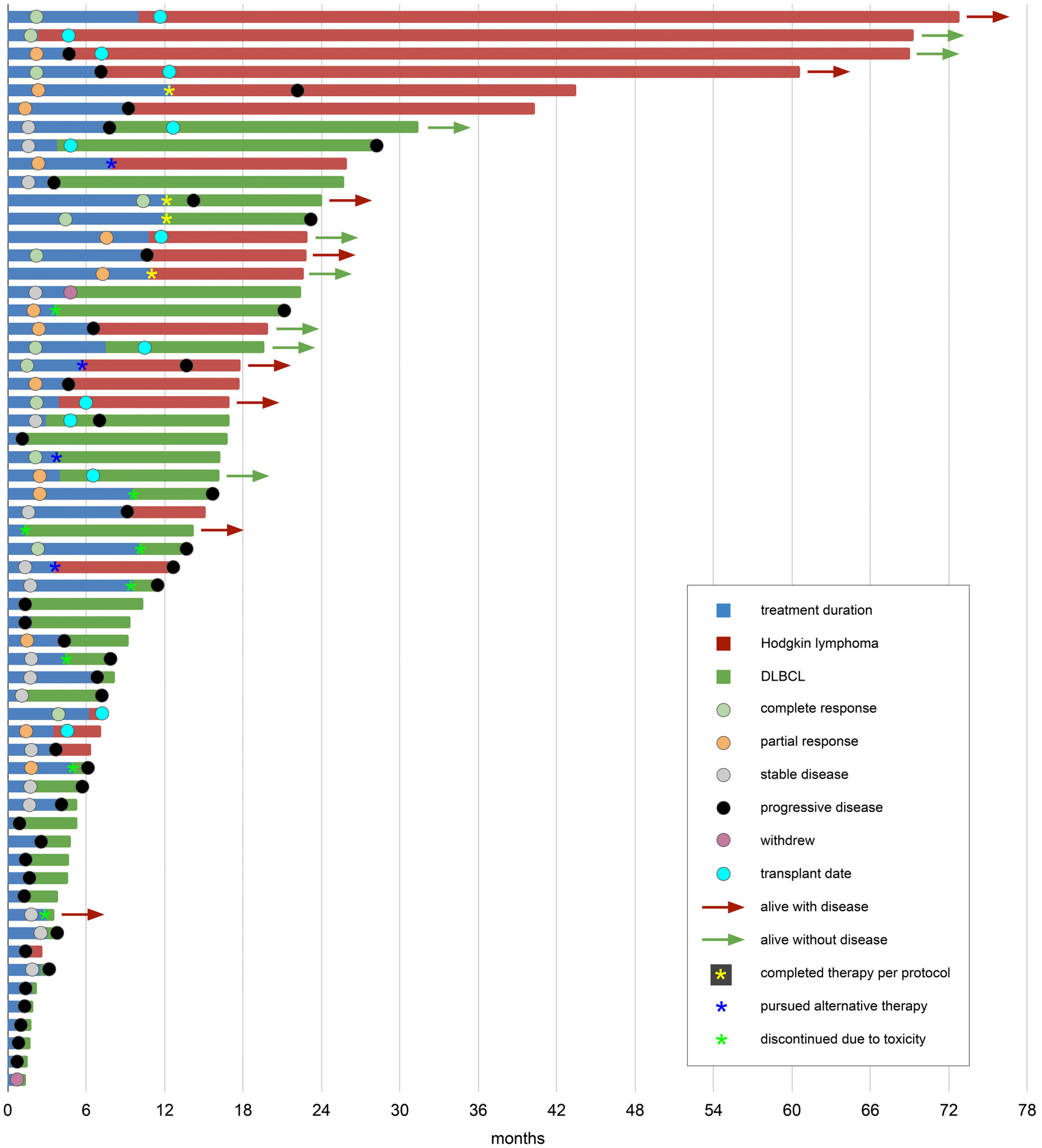

Figure 2. Swimmer's plot for patients in the diffuse large $B-c e l l$ lymphoma $(n=39)$ and classical Hodgkin lymphoma ( $n=20)$ cohorts. The plot includes treatment duration, duration of follow-up, best responses, time of progression, reason for treatment discontinuation, and time of subsequent transplantation. DLBCL: diffuse large B-cell lymphoma.

or 4 in severity in the phase I study, and Table 4 summarizes the $A E$ in the phase II study. In the phase II study, grade 3 or 4 hematologic AE were common, and included anemia $(n=27)$, lymphopenia $(n=39)$, neutropenia $(n=43)$, thrombocytopenia $(n=40)$, and leukocytosis $(n=37)$. Common grade 12 non-hematologic AE included alanine transaminase (ALT) and aspartate transaminase (AST) elevation, hypertriglyceridemia, hyperglycemia, hypocalcemia, hypokalemia, anorexia, fatigue, and rash. Grade 3 or 4 non-hematologic AE were uncommon, with only fatigue occurring in greater than $10 \%$ of patients in the phase II study. Three grade $5 \mathrm{AE}$ were observed that were possibly related to TEM/LEN, and were colonic perforation, myocardial infarction, and sepsis. There was one case of grade 3 pneumonitis in the phase I study and one case of grade 3 thromboembolism in the phase II study. There were no secondary malignancies identified. There were ten deaths on study: one in the phase I portion due to disease, and nine in the phase II study, three of which were the aforementioned grade $5 \mathrm{AE}$, four due to disease, and two which were unrelated to the study ( 1 seizure, 1 infectious pneumonia occurring several months after receiving a single dose of TEM/LEN).

\section{Discussion}

Despite significant advances, there remains a need to identify safe, rational and efficacious regimens for re- 
Table 3. Primary and secondary outcomes: rates of complete response, overall response, and survival for all three cohorts, including the subset of Hodgkin lymphoma patients in the exploratory cohort.

\begin{tabular}{|c|c|c|c|c|}
\hline & \multirow[t]{2}{*}{ DLBCL $(n=39)$} & \multirow[t]{2}{*}{ FL $(n=15)$} & \multicolumn{2}{|c|}{ Exploratory cohort $(n=39)$} \\
\hline & & & $\begin{array}{l}\text { Entire cohort } \\
\qquad(N=39)\end{array}$ & $\begin{array}{l}\text { Hodgkin lymphoma } \\
\qquad(\mathrm{N}=20)\end{array}$ \\
\hline \multicolumn{5}{|l|}{ Primary outcomes } \\
\hline Complete response (\%) & $5(12.8)$ & $5(33.3)$ & $7(17.9)$ & $7(35)$ \\
\hline Overall response (\%) & $10(25.6)$ & $7(46.6)$ & $25(64.1)$ & $16(80)$ \\
\hline \multicolumn{5}{|l|}{ Secondary outcomes } \\
\hline PFS (median, 90\% Cl) & $\begin{array}{l}7.0 \text { months } \\
(3.5-8.0)\end{array}$ & $\begin{array}{c}27.7 \text { months } \\
(6.5-35.8)\end{array}$ & $\begin{array}{l}7.0 \text { months } \\
(4.6-9.9)\end{array}$ & $\begin{array}{l}9.2 \text { months } \\
(4.6-25.5)\end{array}$ \\
\hline OS (median, $90 \% \mathrm{Cl}$ ) & $\begin{array}{c}9.1 \text { months } \\
6.0-16.0)\end{array}$ & $\begin{array}{l}35.8 \text { months } \\
(18.8-\mathrm{NE})^{1}\end{array}$ & $\begin{array}{c}25.5 \text { months } \\
(10.8-60.6)\end{array}$ & $\begin{array}{c}39.6 \text { months } \\
(17.4-N R)^{2}\end{array}$ \\
\hline DOR (median, 90\% Cl) & $\begin{array}{c}13.8 \text { months }^{3} \\
(4.1-19.0)\end{array}$ & $\begin{array}{c}26.5 \text { months }^{4} \\
(17.6-35.2)\end{array}$ & $\begin{array}{c}5.5 \text { months }^{5} \\
(2.6-23.7)\end{array}$ & $\begin{array}{c}8.1 \text { months }^{6} \\
(5.1-38.3)\end{array}$ \\
\hline Follow-up (median, range) & $\begin{array}{c}8.0 \text { months } \\
(1.3-30.9)\end{array}$ & $\begin{array}{l}18.8 \text { months } \\
(5.9-73.9)\end{array}$ & $\begin{array}{c}13.1 \text { months } \\
(1.0-71.6)\end{array}$ & $\begin{array}{c}20.9 \text { months } \\
(2.6-71.6)\end{array}$ \\
\hline
\end{tabular}

${ }^{1} \mathrm{NE}$ : not estimable; ${ }^{2} \mathrm{NR}$ : not reached; ${ }^{3} n=10 ;{ }^{4} n=7 ;{ }^{5} n=25 ; 6 n=16 ; \mathrm{Cl}$ : confidence interval; FL: follicular lymphoma; DLBCL: diffuse large B-cell lymphoma; PFS: progression-free survival; OS: overall survival: DOR: duration of response.

A

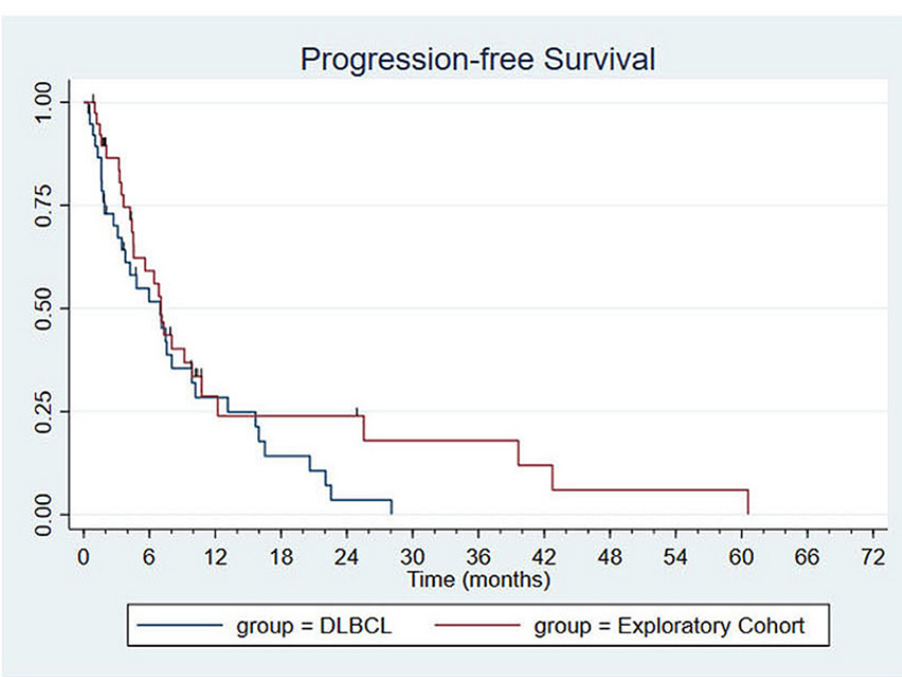

C

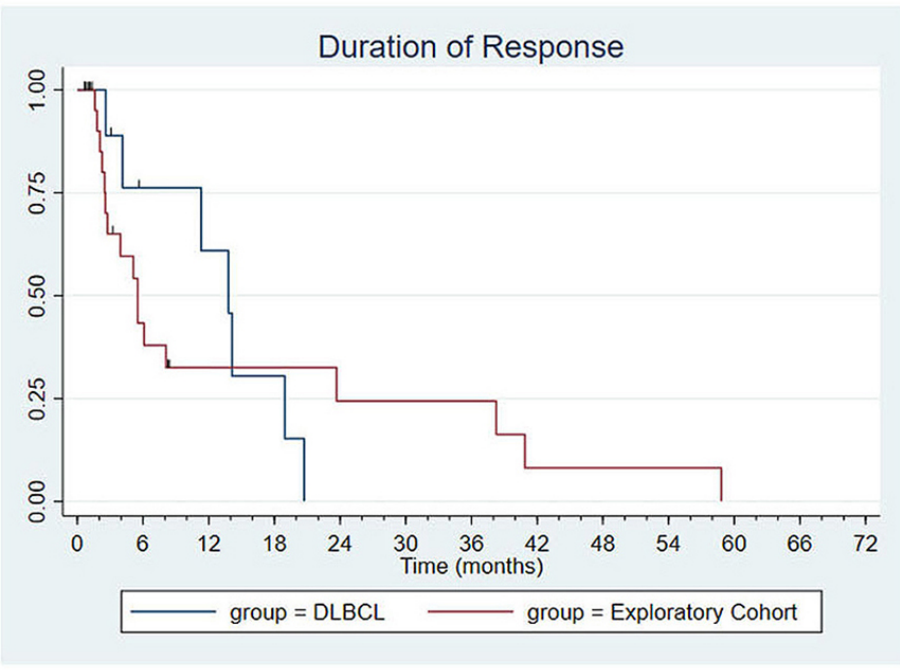

B

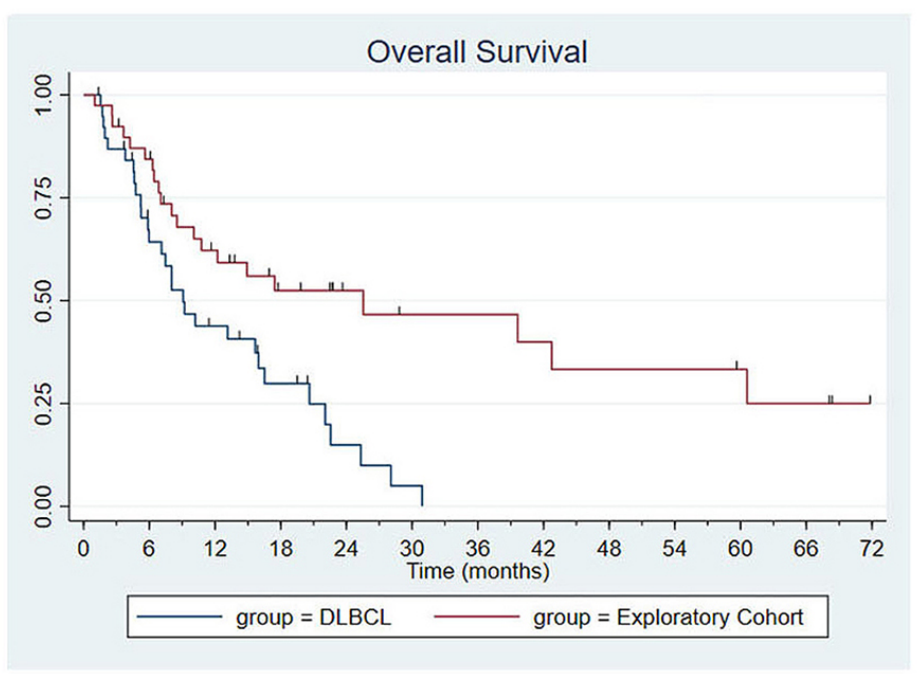

Figure 3. Kaplan-Meier curves for progression-free survival, overall survival and duration of response in the diffuse large B-cell lymphoma $(n=39)$ and exploratory cohorts $(n=39)$. The duration of response curves are based on 10 and 25 responders, respectively. DLBCL: diffuse large B-cell lymphoma.

lapsed and refractory lymphomas. A promising target is the PAM signaling axis, with mTOR representing one of the penultimate components impacting mRNA translation, autophagy, and cell survival. ${ }^{5}$ LEN, with its pleiotropic effects on malignant and non-malignant cells, is a rational combination partner. This phase I/II clinical trial investigated the safety and efficacy of the first-generation mTOR inhibitor TEM plus LEN across several lymphoma subtypes. The phase I component identified LEN $20 \mathrm{mg}$ on days 1 through 21 of a 28 -day cycle as the recommended phase II dose when combined with weekly TEM at $25 \mathrm{mg}$. Preliminary efficacy and acceptable toxicity in the phase I study prompted the phase II trial, which shows promising activity of TEM/LEN combination therapy in relapsed and 
refractory $\mathrm{cHL}$. Among $20 \mathrm{cHL}$ patients with very heavily pretreated disease, including a median of six prior lines of therapy and near universal BV exposure, we found an ORR of $80 \%$, allowing many to be bridged to subsequent allogeneic stem cell transplantation.

mTOR inhibitors, both alone and in combination, have been previously tested in lymphoid malignancies. Early research on mTOR inhibitors focused on relapsed MCL due to the putative role of mTOR inhibition in suppressing downstream overexpression of cyclin D1. ${ }^{5,7}$ Initial phase II trials of single-agent TEM in MCL demonstrated an ORR of $38-41 \%, 7,21$ culminating in a phase III study of TEM compared to investigator's choice of therapy which demonstrated a superior PFS and ORR with TEM. ${ }^{8}$ Further mTOR-focused clinical research with the rapamycin analog everolimus demonstrated modest single-agent activity in relapsed aggressive lymphomas with an ORR of $30-38 \%,{ }^{22}$ with an even higher ORR of $70 \%$ in WM. ${ }^{23}$ Given the encouraging single-agent activity of mTOR inhibitor monotherapy, there has been ongoing research into synergistic combinations. ${ }^{3}$ A phase II study of TEM in combination with rituximab for relapsed $M C L$ found an improved ORR of $59 \%,{ }^{24}$ and preliminary data have been presented on mTOR inhibitors in combination with the BCL2 inhibitor venetoclax ${ }^{25}$ as well as triplet therapy with mTOR inhibitors, BTK inhibitors and pomalidomide, ${ }^{26}$ all with encouraging early reports.

Among NHL patients, our trial identified modest activity in DLBCL, with similar response rates compared to our previous phase II clinical trial of TEM monotherapy in DLBCL. ${ }^{9}$ Despite limited responses, we observed a median DOR of 13.8 months in heavily-pretreated patients with aggressive disease, a considerably longer DOR than only 2.4 months observed with single-agent TEM. ${ }^{9}$ These findings with TEM/LEN may be related to cell-of-origin; seven of ten DLBCL responders, including three of five complete responders, harbored an ABC phenotype where LEN is known to have preferential activity. ${ }^{29}$ Others have shown that upstream inhibition of PAM signaling may be active in DLBCL and related to PIK3CA amplification; ${ }^{3,27}$ to this point, the $\mathrm{PI} 3 \mathrm{~K}$ inhibitor copanlisib demonstrated single-agent activity in relapsed DLBCL with an ORR of 32\% in ABC-type and $13 \%$ in GCB-type. ${ }^{28}$ Since our study was conducted, the management options for relapsed and refractory DLBCL have expanded substantially and now includes chimeric antigen receptor T (CAR-T) cell therapy, and the role of less aggressive regimens such as TEM/LEN is unclear. TEM/LEN may be an option for patients unable to tolerate CAR-T cells, particularly for patients with ABC DLBCL, or given the impact of PI3K inhibition on CAR-T cell activity and persistence in vivo, there may be a role to further explore PAM axis inhibition following CAR-T cells. ${ }^{30,31}$

The FL cohort was unfortunately closed due to low accrual, which may be related to the competitive landscape
Table 4. Summary of reported toxicities in the phase II study occurring in either greater than $10 \%$ of patients or grade $\geq 3$ in severity.

\begin{tabular}{|c|c|c|c|}
\hline Toxicity & All grades & Grade 3-4 & Grade 5 \\
\hline \multicolumn{4}{|l|}{ Non-hematologic toxicity } \\
\hline ALT increased & $39(42 \%)$ & $1(1 \%)$ & 0 \\
\hline Alk phos increased & $31(33 \%)$ & $1(1 \%)$ & 0 \\
\hline Anorexia & $37(40 \%)$ & $4(4 \%)$ & 0 \\
\hline AST increased & $38(41 \%)$ & 0 & 0 \\
\hline Bleeding & $10(11 \%)$ & 0 & 0 \\
\hline Chills & $10(11 \%)$ & 0 & 0 \\
\hline Hypercholesterolemia & $28(30 \%)$ & 0 & 0 \\
\hline Colonic perforation & 0 & 0 & $1(1 \%)$ \\
\hline Constipation & $32(34 \%)$ & 0 & 0 \\
\hline Cough & $15(16 \%)$ & 0 & 0 \\
\hline Creatinine increased & $23(25 \%)$ & $1(1 \%)$ & 0 \\
\hline Diarrhea & $28(20 \%)$ & $2(2 \%)$ & 0 \\
\hline Dysgeusia & $21(23 \%)$ & 0 & 0 \\
\hline Edema & $29(31 \%)$ & $1(1 \%)$ & 0 \\
\hline Fatigue & $65(70 \%)$ & $11(12 \%)$ & 0 \\
\hline Fever & $22(24 \%)$ & $6(6 \%)$ & 0 \\
\hline Hypercalcemia & $10(11 \%)$ & 0 & 0 \\
\hline Hyperglycemia & $69(74 \%)$ & $8(9 \%)$ & 0 \\
\hline Hypernatremia & $10(11 \%)$ & 0 & 0 \\
\hline Hypertension & $10(11 \%)$ & $2(2 \%)$ & 0 \\
\hline Hypertriglyceridemia & $35(38 \%)$ & $5(5 \%)$ & 0 \\
\hline Hypoalbuminemia & $26(28 \%)$ & $1(1 \%)$ & 0 \\
\hline Hypocalcemia & $50(54 \%)$ & $4(4 \%)$ & 0 \\
\hline Hypokalemia & $56(60 \%)$ & $8(9 \%)$ & 0 \\
\hline Hypomagnesemia & $25(27 \%)$ & $2(2 \%)$ & 0 \\
\hline Hyponatremia & $19(20 \%)$ & $2(2 \%)$ & 0 \\
\hline Hypophosphatemia & $22(24 \%)$ & $3(3 \%)$ & 0 \\
\hline Infection & $11(12 \%)$ & $2(2 \%)$ & 0 \\
\hline Myalgia & $9(10 \%)$ & $1(1 \%)$ & 0 \\
\hline Myocardial infarction & 0 & 0 & $1(1 \%)$ \\
\hline Nausea & $26(28 \%)$ & $2(2 \%)$ & 0 \\
\hline Neuropathy & $16(17 \%)$ & 0 & 0 \\
\hline Pain & $11(12 \%)$ & $1(1 \%)$ & 0 \\
\hline Pruritus & $30(32 \%)$ & $1(1 \%)$ & 0 \\
\hline Rash & $59(63 \%)$ & $7(8 \%)$ & 0 \\
\hline Sepsis & 0 & 0 & $1(1 \%)$ \\
\hline Stomatitis & $22(24 \%)$ & $3(3 \%)$ & 0 \\
\hline Thromboembolism & $4(4 \%)$ & $1(1 \%)$ & 0 \\
\hline \multicolumn{4}{|l|}{ Hematologic toxicity } \\
\hline Anemia & 77 (83\%) & 27 (29\%) & 0 \\
\hline Lymphopenia & $66(71 \%)$ & $39(42 \%)$ & 0 \\
\hline Neutropenia & $63(68 \%)$ & $43(46 \%)$ & 0 \\
\hline Thrombocytopenia & $76(82 \%)$ & $40(43 \%)$ & 0 \\
\hline Leukocytosis & $76(82 \%)$ & $37(40 \%)$ & 0 \\
\hline
\end{tabular}

ALT: alanine transaminase; Alk phos: alkaline phosphatase; AST: aspartate transaminase. 


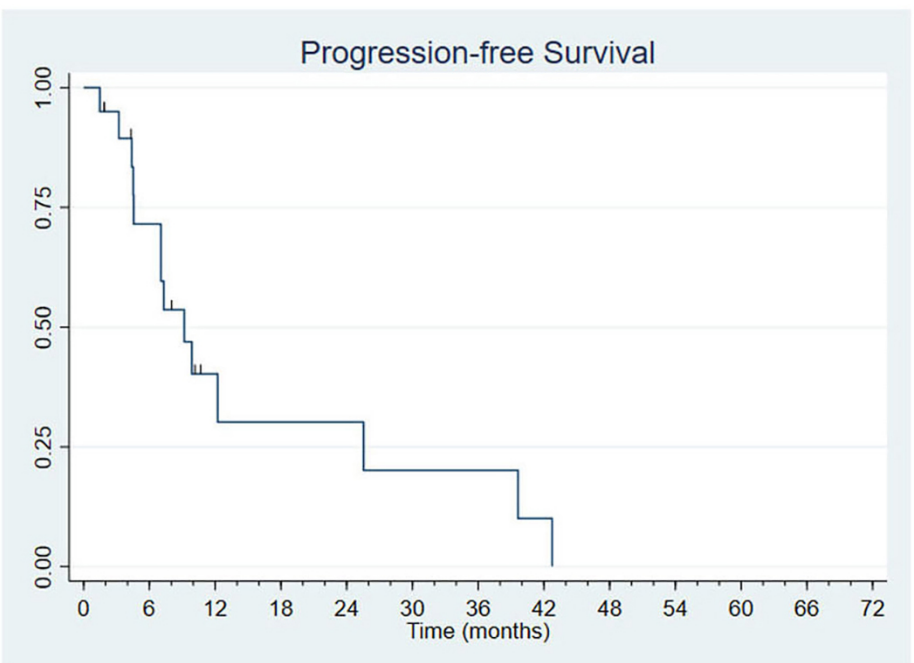

C

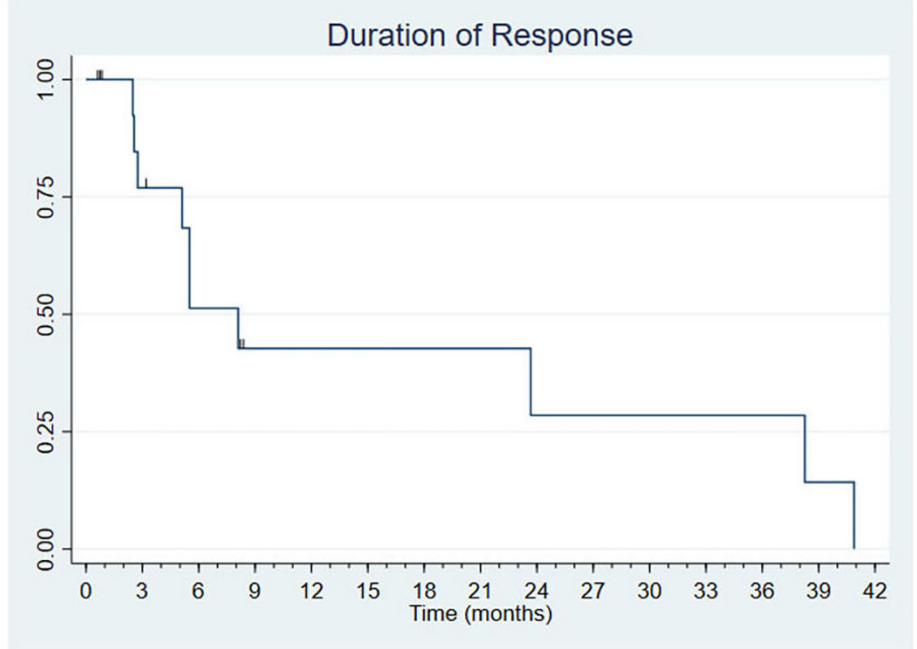

B

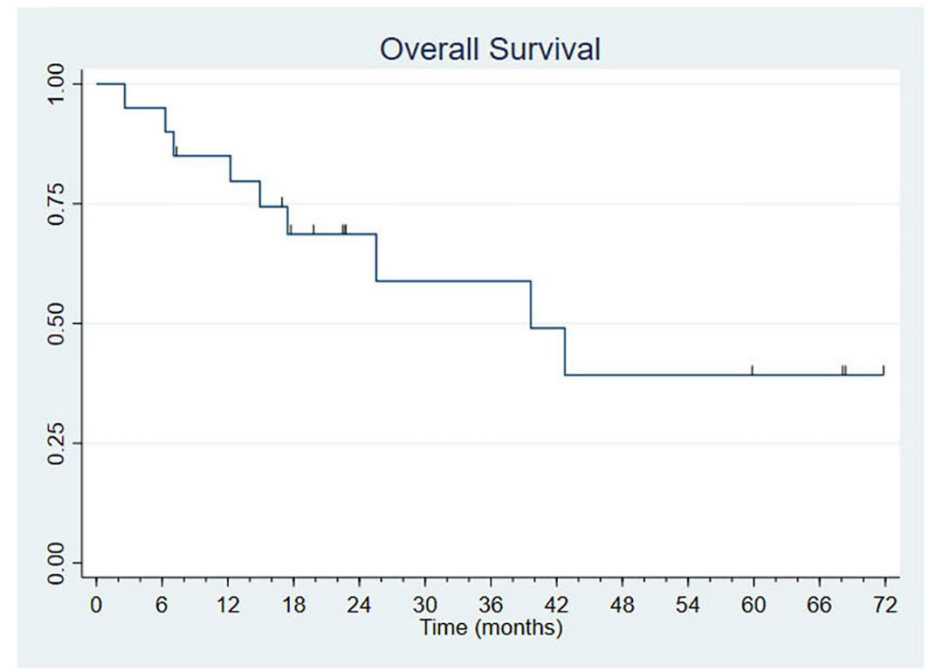

Figure 4. Kaplan-Meier curves for progression-free survival, overall survival and duration of response for the classical Hodgkin lymphoma patients $(n=20)$ in the exploratory cohort. The duration of response curve is based on 16 responders.

of effective therapies both as part of clinical trials as well as routine clinical care. We are encouraged by the early activity of TEM/LEN in FL, but have insufficient data to comment further.

In the exploratory cohort that enrolled other lymphoma histologies, we observed promising activity with TEM/LEN in T-NHL, with two-thirds of patients responding. Others have shown activity with both mTOR inhibitors and LEN in T-NHL, with ORR of $44 \%$ with single-agent everolimus ${ }^{32}$ and ORR of $26 \%$ with single-agent LEN. ${ }^{33}$ The activity of LEN in T$\mathrm{NHL}$ may be due to overexpression of Akt in T-NHL, ${ }^{34}$ with evidence of possible synergism between TEM and LEN in this study. There is preclinical rationale for combination targeting of the PAM axis in T-NHL, with dual mTOR and PI3K inhibition demonstrating activity in cutaneous T-NHL cell lines. ${ }^{35}$ The PI3K pathway appears to be particularly active in T-NHL, ${ }^{36}$ with a phase I trial of duvelisib demonstrating ORR of $50.0 \%$ in peripheral T-NHL and $31.6 \%$ in cutaneous $\mathrm{T}^{-\mathrm{NHL}^{37}}$ and a phase I trial of novel dual PI3K $\delta / \gamma$ inhibitor tenalisib demonstrating ORR of $46 \%$ in relapsed $\mathrm{T}-\mathrm{NHL} .{ }^{38}$ Further investigation of PAM inhibition, with or without LEN, appears warranted.

The most promising signal of activity in our study was observed in relapsed and refractory $\mathrm{cHL}$. While our study was conducted prior to the era of checkpoint inhibitors (CPI), $\mathrm{CHL}$ patients enrolled in this trial were heavily pretreated, with a median of six prior regimens, with near universal prior BV exposure and the majority having relapsed despite prior ASCT. We observed an ORR of $80 \%$ with a CR rate of $35 \%$, which compares favorably with expected outcomes following either single-agent BV or CPI. 39,40 This may be due to constitutive activation of the PAM axis in CHL with downstream activation of NF-KB promoting cell survival and proliferation. ${ }^{6,41}$ Others have explored mTOR inhibition as monotherapy and in combination with other agents in CHL. Based on preclinical work demonstrating cell cycle arrest and autophagy induced by TEM in CHL cell lines, a phase II trial of single-agent everolimus in 19 patients with relapsed $\mathrm{cHL}$ was conducted and found an ORR of $47 \% .{ }^{42}$ Combined sirolimus and vorinostat had an ORR of $55 \%$ in relapsed CHL. ${ }^{43}$ However, combination therapy with TEM/LEN had higher response rates than LEN (ORR 19\%) ${ }^{15}$ or mTOR inhibitors (ORR 47\%) alone, ${ }^{42,44}$ supporting dual targeting of the PAM axis in CHL. Targeting other components of the PAM axis, such as PI3K inhibition, has demonstrated modest response rates, with an ORR of $20 \%$ with single-agent idelalisib in relapsed $\mathrm{cHL} .{ }^{45}$ Additional areas to consider include combination with CPI, as mTOR inhibition may induce PD-L1 expression and encourage immune escape in preclinical models. ${ }^{46}$ Further, a recent study of the mTOR inhibitor everolimus in combination with ruxolitinib, an oral JAK inhibitor which targets the JAK/STAT pathway that is a putative escape mechanism to $\mathrm{CPI},{ }^{47}$ demonstrated an ORR of $79 \%$ in relapsed $\mathrm{CHL}$ that had progressed after $\mathrm{CPI}$ ther- 
apy. ${ }^{48}$ Overall, combined TEM/LEN had encouraging activity and supports further investigation in $\mathrm{CHL}$.

The combination of TEM/LEN therapy was feasible in this study, with hematologic AE being most commonly experienced. Pneumonitis is a previously-reported complication of mTOR inhibitor therapy, ${ }^{49}$ but we found only one case of grade 3 pneumonitis occurring in this study. LEN treatment has been associated with a risk for thromboembolism, ${ }^{50}$ and there was one grade 3 thromboembolism in the study. Although there is significant experience with weekly TEM dosing, it is clearly inconvenient for patients, and there is a suggestion that higher TEM dosing may be more efficacious than the $25 \mathrm{mg}$ dose selected for evaluation in this study. ${ }^{8}$ Overall, the combination of TEM/LEN demonstrated encouraging activity in a heavily pretreated group of patients with relapsed and refractory $\mathrm{CHL}$, and could be a platform for future investigations. In contrast, the addition of LEN to TEM did not show significant improvement over our prior TEM monotherapy study in either DLBCL or FL, although we did find encouraging response duration among the few responding patients and preliminary activity in a very small cohort of T-NHL patients. Two major unanswered questions are whether first-generation agents such as TEM or everolimus provide optimal mTOR inhibition, ${ }^{5}$ and whether upstream inhibition of PI3K should supplant our approach given the number of agents in this area. Future research exploring novel therapeutics or combinations of therapeutics acting on the PAM axis, particularly in patients who cannot tolerate transplantation or i.e., CAR-T cell therapy and have heavily pre-treated lymphomas, is warranted.

\section{Disclosures}

AM received funding from the National Cancer Institute (NCI), Merck and a T32 institutional training grant (5T32CA009566); JK is a member on an entity's Board of Directors or advisory committees of SeattleGenetics, Verastem, Morphosys and Karyopharm, is part of the speakers bureau of Kite/Gilead and consults for Regeneron; AM received funding from a National Cancer Institute (NCI) T32 institutional training grant (5T32CA009566; ASK is currently employed by Amgen and is a current equity holder in a publicly-traded company (Amgen); AMP is currently employed by Daiichi-Sankyo and is a current equity holder in a publicly-traded company (AbbVie); TGK, PASF, SN, KR, $B G S, K C, K V B$ and $A P R$ have no conflicts of interest to declare; SMS consults for Gilead, Celgene/BMS, Morphosys, Janssen, Bantam, Karyopharm, Genentech, TG Therapeutics, Bayer, Kite and Seattle Genetics.

\section{Contributions}

AM wrote the manuscript; JK, TGK, PASF, ASK, AMP,SN, KR, $B G S, K C$ and $A P R$ performed research; KVB supervised the study and performed research; and SMS wrote the protocol, wrote the manuscript, supervised the study and performed research.

\section{Data Sharing Statement}

Within 6 months of publication, a de-identified dataset will be made publically available containing the data used to generate the primary and secondary analyses reported in this manuscript.

\section{References}

1. Westin JR. Status of PI3K/Akt/mTOR pathway inhibitors in lymphoma. Clin Lymphoma Myeloma Leuk. 2014; 14(5):335-342.

2. Curran E, Smith SM. Phosphoinositide 3-kinase inhibitors in lymphoma. Curr Opin Oncol. 2014;26(5):469-475.

3. Lee J-HS, Vo T-T, Fruman DA. Targeting mTOR for the treatment of B cell malignancies. Br J Clin Pharmacol.

2016;82(5):1213-1228.

4. Saxton RA, Sabatini DM. mTOR signaling in growth, metabolism, and disease. Cell. 2017;168(6):960-976.

5. Argyriou P, Economopoulou P, Papageorgiou S. The role of mTOR inhibitors for the treatment of B-cell lymphomas. Adv Hematol. 2012;2012:435342.

6. Márk Á, Hajdu M, Váradi Z, et al. Characteristic mTOR activity in Hodgkin-lymphomas offers a potential therapeutic target in high risk disease - a combined tissue microarray, in vitro and in vivo study. BMC Cancer. 2013;13(1):250.

7. Witzig TE, Geyer SM, Ghobrial I, et al. Phase II trial of singleagent temsirolimus (CCl-779) for relapsed mantle cell lymphoma. J Clin Oncol. 2005;23(23):5347-5356.

8. Hess G, Herbrecht R, Romaguera J, et al. Phase III study to evaluate temsirolimus compared with investigator's choice therapy for the treatment of relapsed or refractory mantle cell lymphoma. J Clin Oncol. 2009;27(23):3822-3829.
9. Smith SM, van Besien K, Karrison T, et al. Temsirolimus has activity in non-mantle cell non-Hodgkin's lymphoma subtypes: the University of Chicago Phase II Consortium. J Clin Oncol. 2010; 28(31):4740-4746.

10. Gribben JG, Fowler N, Morschhauser F. Mechanisms of action of lenalidomide in B-cell non-Hodgkin lymphoma. J Clin Oncol. 2015;33(25):2803-2811.

11. Montanari F, Diefenbach CSM. Hodgkin lymphoma: targeting the tumor microenvironment as a therapeutic strategy. Clin Adv Hematol Oncol. 2015;13(8):518-524.

12. Lu G, Middleton RE, Sun H, et al. The myeloma drug lenalidomide promotes the cereblon-dependent destruction of ikaros proteins. Science. 2014;343(6168):305-309.

13. Kotla V, Goel S, Nischal S, et al. Mechanism of action of lenalidomide in hematological malignancies. J Hematol Oncol. 2009;2(1):36.

14. Arora M, Gowda S, Tuscano J. A comprehensive review of lenalidomide in B-cell non-Hodgkin lymphoma. Therapeutic Adv Hematol. 2016;7(4):209-221.

15. Fehniger TA, Larson S, Trinkaus K, et al. A phase 2 multicenter study of lenalidomide in relapsed or refractory classical Hodgkin lymphoma. Blood. 2011;118(19):5119-5125.

16. Cheson BD, Pfistner B, Juweid ME, et al. Revised response 
criteria for malignant lymphoma. J Clin Oncol. 2007;25(5):579-586.

17. Treon SP. Update on treatment recommendations from the third international workshop on waldenstrom's macroglobulinemia. Blood. 2006;107(9):3442-3446.

18. Simon R. Optimal two-stage designs for phase II clinical trials. Control Clin Trials. 1989;10(1):1-10.

19. Kaplan EL, Meier P. Nonparametric estimation from incomplete observations. J Am Stat Assoc. 1958;53:457-481.

20. Brookmeyer R, Crowley J. A confidence interval for the median survival time. Biometrics. 1982;38(1):29-41.

21. Ansell SM, Inwards DJ, Rowland KM, et al. Low-dose, singleagent temsirolimus for relapsed mantle cell lymphoma: a phase 2 trial in the North Central Cancer Treatment Group. Cancer. 2008;113(3):508-514.

22. Witzig TE, Reeder CB, LaPlant BR, et al. A phase II trial of the oral mTOR inhibitor everolimus in relapsed aggressive lymphoma. Leukemia. 2011;25(2):341-347.

23. Ghobrial IM, Gertz M, LaPlant B, et al. Phase ii trial of the oral mammalian target of rapamycin inhibitor everolimus in relapsed or refractory Waldenström macroglobulinemia. J Clin Oncol. 2010; 28(8):1408-1414.

24. Ansell SM, Tang H, Kurtin PJ, et al. Temsirolimus and rituximab in patients with relapsed or refractory mantle cell lymphoma: a phase 2 study. Lancet Oncol. 2011;12(4):361-368.

25. Tarantelli C, Gaudio E, Hillmann P, et al. The novel TORC1/2 kinase inhibitor PQR620 has anti-tumor activity in lymphomas as a single agent and in combination with venetoclax. Cancers. 2019;11(6):775.

26. Mato AR, Schuster SJ, Foss FM, et al. A once daily, oral, triple combination of BTK inhibitor, mTOR inhibitor and IMiD for treatment of relapsed/refractory Richter's transformation and de novo diffuse large B-cell lymphoma. Blood. 2020;136(Suppl 1):S21-22.

27. Godfrey J, Kang W, Huang L, et al. Macrophage activation by dual PI3K- $\delta / \gamma$ inhibition enhances anti-CD47-mediated phagocytosis and prolongs survival in DLBCL. Blood. 2020;136(Suppl 1):40.

28. Lenz G, Hawkes E, Verhoef G, et al. Single-agent activity of phosphatidylinositol 3-kinase inhibition with copanlisib in patients with molecularly defined relapsed or refractory diffuse large B-cell lymphoma. Leukemia. 2020;34(8):2184-2197.

29. Zhang L-H, Kosek J, Wang M, Heise C, Schafer PH, Chopra R. Lenalidomide efficacy in activated B-cell-like subtype diffuse large B-cell lymphoma is dependent upon IRF4 and cereblon expression. Br J Haematol. 2013;160(4):487-502.

30. Zheng W, O'Hear CE, Alli R, et al. PI3K orchestration of the in vivo persistence of chimeric antigen receptor-modified $T$ cells. Leukemia. 2018;32(5):1157-1167.

31. Dwyer CJ, Arhontoulis DC, Rangel Rivera GO, et al. Ex vivo blockade of PI3K gamma or delta signaling enhances the antitumor potency of adoptively transferred CD8+ T cells. Eur $\mathrm{J}$ Immunol. 2020;50(9):1386-1399.

32. Witzig TE, Reeder C, Han JJ, et al. The mTORC1 inhibitor everolimus has antitumor activity in vitro and produces tumor responses in patients with relapsed T-cell lymphoma. Blood. 2015;126(3):328-335.

33. Toumishey E, Prasad A, Dueck G, et al. Final report of a phase 2 clinical trial of lenalidomide monotherapy for patients with Tcell lymphoma. Cancer. 2015; 121(5):716-723.

34. Hong JY, Hong ME, Choi MK, et al. The clinical significance of activated p-AKT expression in peripheral T-cell lymphoma. Anticancer Res. 2015;35(4):2465-2474.

35. Bresin A, Cristofoletti C, Caprini E, et al. Preclinical evidence for targeting PI3K/mTOR signaling with dual-inhibitors as a therapeutic strategy against cutaneous T-cell lymphoma. J Invest Dermatol. 2020;140(5):1045-1053.

36. Huang $D$, Song TL, Nairismägi $M$, et al. Evaluation of the PIK3 pathway in peripheral T-cell lymphoma and NK/T-cell lymphoma. Br J Haematol. 2020;189(4):731-744.

37. Horwitz SM, Koch R, Porcu P, et al. Activity of the PI3K- $\delta, \gamma$ inhibitor duvelisib in a phase 1 trial and preclinical models of Tcell lymphoma. Blood. 2018;131(8):888-898.

38. Huen A, Haverkos BM, Zain J, et al. Phase I/Ib study of tenalisib (Rp6530), a dual PI3K $\delta / \gamma$ inhibitor in patients with relapsed/refractory T-cell lymphoma. Cancers. 2020;12(8):2293.

39. De Goycoechea D, Stalder G, Martins F, Duchosal MA. Immune checkpoint inhibition in classical Hodgkin lymphoma: from early achievements towards new perspectives. J Oncol. 2019;2019:9513701.

40. Mina A, Vakkalagadda C, Pro B. Novel therapies and approaches to relapsed/refractory HL beyond chemotherapy. Cancers. 2019;11(3):421.

41. Dutton A, Reynolds GM, Dawson CW, Young LS, Murray PG. Constitutive activation of phosphatidyl-inositide 3 kinase contributes to the survival of Hodgkin's lymphoma cells through a mechanism involving Akt kinase and mTOR. J Pathol. 2005; 205(4):498-506.

42. Johnston PB, Inwards DJ, Colgan JP, et al. A phase II trial of the oral mTOR inhibitor everolimus in relapsed Hodgkin lymphoma. Am J Hematol. 2010;85(5):320-324.

43. Janku F, Park H, Call SG, et al. Safety and efficacy of vorinostat plus sirolimus or everolimus in patients with relapsed refractory Hodgkin lymphoma. Clin Cancer Res. 2020;26(21):5579-5587.

44. Johnston PB, Pinter-Brown LC, Warsi G, White K, Ramchandren R. Phase 2 study of everolimus for relapsed or refractory classical Hodgkin lymphoma. Exp Hematol Oncol. 2018;7(1):12.

45. Gopal AK, Fanale MA, Moskowitz CH, et al. Phase II study of idelalisib, a selective inhibitor of PI3Kס, for relapsed/refractory classical Hodgkin lymphoma. Ann Oncol. 2017;28(5):1057-1063.

46. Sun S-Y. Searching for the real function of mTOR signaling in the regulation of PD-L1 expression. Transl Oncol. 2020;13(12): 100847.

47. Marabelle A, Aspeslagh S, Postel-Vinay S, Soria J-C. JAK mutations as escape mechanisms to anti-PD-1 therapy. Cancer Discov. 2017;7(2):128-130.

48. Svoboda J, Barta SK, Landsburg DJ, et al. Everolimus plus itacitinib in relapsed/refractory classical Hodgkin lymphoma: results of a phase I/II investigator initiated trial (EVITA study). Blood. 2020; 136(Suppl1):S20-21.

49. Zhang X, Ran Y, Wang K. Risk of mTOR inhibitors induced severe pneumonitis in cancer patients: a meta-analysis of randomized controlled trials. Future Oncol. 2016; 12(12):1529-1539.

50. Al-Ani F, Bermejo JMB, Mateos M-V, Louzada M. Thromboprophylaxis in multiple myeloma patients treated with lenalidomide - a systematic review. Thromb Res. 2016;141:84-90. 